\title{
XFEM Modelling of Multi-holes Plate with Single-row and Staggered Holes Configurations
}

\author{
Khairi Supar ${ }^{1 *}$, and Hilton Ahmad ${ }^{1}$ \\ ${ }^{1}$ Faculty of Civil and Environmental Engineering, Universiti Tun Hussein Onn Malaysia, 86400 Parit \\ Raja, Batu Pahat, Johor Darul Ta'zim
}

\begin{abstract}
Joint efficiency is the key to composite structures assembly design, good structures response is dependent upon multi-holes behaviour as subjected to remote loading. Current benchmarking work were following experimental testing series taken from literature on multi-holes problem. Eleven multi-hole configurations were investigated with various pitch and gage distance of staggered holes and non-staggered holes (singlerow holes). Various failure modes were exhibited, most staggered holes demonstrates staggered crack path but non-staggered holes series displayed crack path along net-section plane. Stress distribution were carried out and good agreement were exhibited in experimental observation as reported in the respective literature. Consequently, strength prediction work were carried out under quasi-static loading, most showed discrepancy between $8 \%-31 \%$, better prediction were exhibited in thicker and non-staggered holes plate combinations.
\end{abstract}

\section{Introduction}

Composite materials offer advantages such as superior specific stiffness and strength compared to conventional engineering materials. Traditionally, these materials were incorporated within aerospace and automotive engineering sectors, however due to price drop over the last 40 years, the applicability has been expanded to civil engineering applications. Most structures parts are assembled by using joining techniques, conventionally mechanically fastened joints were preferred but requires the introduction of hole in the composite plates. As a results of large arrays of composite combinations, complex damage morphologies were exhibited and leading to difficulties in strength prediction work.

Due to the existence of discontinuities in the form of flaws, notched and cut-out, the stress raisers at the notch tip are exhibited as found by previous researchers [1]. Most work on open hole problems study only single-hole plate, where the crack initiation and crack propagation were likely to occur along the net-section plane perpendicularly to the loading applied. Compared to single-bolted problems, multi-bolted problem enable by-pass loading to be transferred to the adjacent bolts. Net-tension is associated with stress raisers at the

* Corresponding author: khairisupar@gmail.com 
vicinity of the hole edge, more significantly in staggered hole configurations due to existence of by-pass loading transfer within adjacent holes [2]. It is important to study the effect of multi-hole problems prior of multi-bolt design of composite material to study joint efficiency of multi-bolted joint during composite joining design phase.

In civil engineering structures design, most joining structures were based on multibolted configurations either in single-row or staggered bolts arrangements. Prior to multibolted joint study, it is essential to investigate the structures behaviour of multi-hole problems when subjected to remote loading. In metallic structures, requirement of minimum spacing between adjacent holes is to avoid local crushing to an adjacent hole and maximum spacing requirement to avoid buckling when subjected to compression loading as specified by code of practice [3]. Optimum pitch distances, row spacing, end distance and bolt diameter on multi-fastened of CFRP composites were studied by Chutima [4]. Cunningham [2] found that staggered hole configurations demonstrated lower load capacity as compared to single-row hole configurations counterparts, this is contradict with expected findings. Two staggered holes showed "zig-zag" patterns showing crack propagates diagonally from the loading applied. On the other hand, staggered configurations with three holes able to show two failure modes, i.e., first failure mode showed net section failures following classical "zig-zag" path passing through adjacent holes and second failure mode demonstrates net-section across two transverse hole according to pitch and gage distances. In unidirectional GFRP composites, latter failure mode were exhibited as the pitch, $\mathrm{s}$ is larger than gage distance, $\mathrm{g}$ [2].

Emerging computing technology enable the material designer to predict the strength of engineering materials by using numerical approaches. Formerly, materials engineers and scientist proposed their analytical expressions which are mostly based on simplistic semiempirical expression. However, these limits the applicability to wider problem as these expressions were simplified by reducing the parameter involved and associated contact interactions. Although good predictions in analytical approaches were found, but these classical approaches were based on semi-empirical work that incorporates experimental datasets. Extended Finite Element Method (XFEM) were introduced by Moes [5] and was successfully implemented in predicting single hole [6] and bolted joints [7]. XFEM is extended from classical finite element expression which has enriched function to enable the crack be tracked visually. There are also other numerical techniques available such as cohesive zone model [8] and progressive damage approach [9], but these modelling techniques requires a pre-defined crack path.

Current benchmarking work explores the applicability of XFEM in predicting multihole composite plate problem based on experimental work by Cunningham [2]. The stress distribution on multi-hole were carried out first in order to study the crack path that likely to occur in each multi-hole configurations. The strength prediction based on XFEM were taken place thereafter and validated against experimental datasets taken from Cunningham's work [2].

\section{Finite Element Modelling Frameworks}

Current benchmarking work were based on experimental set-up by Cunningham [2], he implemented GFRP composite plates of two different plate thickness and different multibolt configurations (non-staggered (single-row) and staggered arrangements). Current work incorporated XFEM modelling framework of all testing series understudied and the XFEM strength prediction were validated against experimental results [2]. Finite Element Analysis are divided into three major stages, pre-processing stage, processing stage and postprocessing stage. Pre-processing stage is data input of FEA model and comprising modelling steps, i.e., modelling idealizations, element discretization (meshing), generation 
of geometry and material properties, and loading and boundary conditions. The predicted joint strength and failure modes of staggered hole were compared with experimental results.

\subsection{Model idealization}

Current multi-hole models were generated using ABAQUS CAE Version 6.13. The model developed in present work were based on two-dimensional model following testing series of multi-hole configurations [2]. Two-dimensional model with full plate geometries were developed, there are no surface contact interactions and frictional load transfer were invloved, therefore two-dimensional modelling framework is sufficient.

\subsection{Generation of materials and geometrical properties}

The boundary conditions and applied load were assigned properly according to mechanical testing conditions. The elastic properties of GFRP used in present model were obtained from experimentally determined values by Cunningham [2] and considered as "smearedout" properties as given in Table 1 . The material properties of unnotched strength, $\sigma_{\mathrm{o}}$ were determined independently, however the fracture energy value were not measured, therefore these value is taken based on woven fabric lay-up [1] and regarded as apparent fracture energy value, $\mathrm{G}_{\mathrm{c}}{ }^{*}$. Although it is expected that unidirectional composite plate gives larger fracture energy value than woven fabric system, but no definite values were found in the literature on unidirectional GFRP composite, fracture energy values from woven system [1] was taken in current work.

Table 1. Material properties of GFRP lay-up used in current work based on [2]

\begin{tabular}{|c|c|c|c|c|c|}
\hline $\begin{array}{c}\text { Plate } \\
\text { thickness }\end{array}$ & $\begin{array}{c}\boldsymbol{E}_{\boldsymbol{x}} \\
(\mathbf{G P a})\end{array}$ & $\begin{array}{c}\boldsymbol{E}_{\boldsymbol{y}} \\
(\mathbf{G P a})\end{array}$ & $\mathbf{v}_{\mathbf{x y}}$ & $\begin{array}{c}\mathbf{\sigma}_{\mathbf{o}} \\
(\mathbf{M P a})\end{array}$ & $\begin{array}{c}\mathbf{G}_{\mathbf{c}}{ }^{*} \\
\left(\mathbf{k J} / \mathbf{m}^{2}\right)\end{array}$ \\
\hline $6.4 \mathrm{~mm}$ & 19.9 & 6.4 & 0.2 & 425 & 20.3 \\
\hline $12.7 \mathrm{~mm}$ & 21.8 & 6.9 & 0.2 & 374 & 20.3 \\
\hline
\end{tabular}

Based on Cunningham [2] experimental series, unidirectional GFRP composites plates with nominal plate thickness of $6.4 \mathrm{~mm}$ and $12.7 \mathrm{~mm}$ were tested. All testing plates conducted have plate width, $b=100 \mathrm{~mm}$ and gauge length, $l=200 \mathrm{~mm}$. Constant hole diameter of $13.1 \mathrm{~mm}$ with variation of total number of holes, $\mathrm{N}$, gage distance, $\mathrm{g}$, and stagger pitch, s as shown in Fig. 1 and their associated plate geometries were given in Table 2.

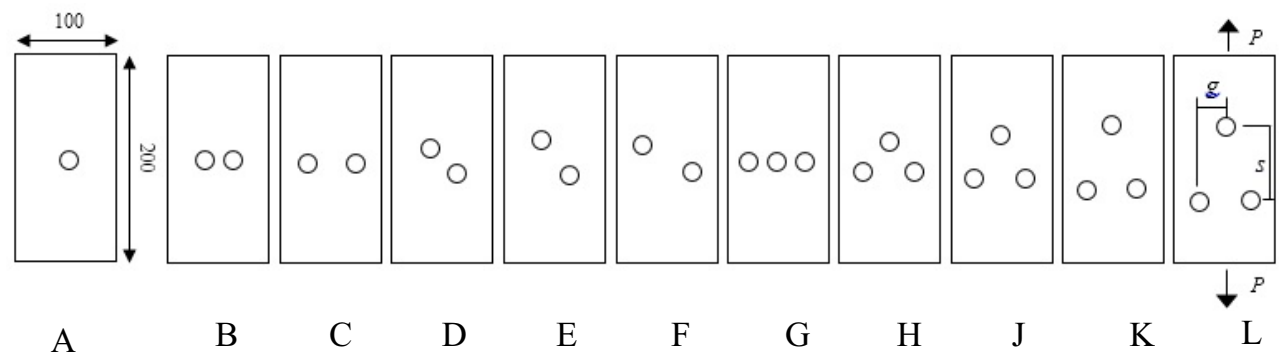

Fig. 1. Testing plate geometry of all testing series tested [2] 
Table 2. Geometry of all multi-hole configurations given in Fig. 1.

\begin{tabular}{|c|c|c|c|c|c|c|c|c|c|c|}
\hline $\begin{array}{c}\text { Testing } \\
\text { Series }\end{array}$ & B & C & D & E & F & G & H & J & K & L \\
\hline $\begin{array}{c}\text { Number } \\
\text { of hole, } \mathbf{N}\end{array}$ & 2 & 2 & 2 & 2 & 2 & 3 & 3 & 3 & 3 & 3 \\
\hline $\begin{array}{c}\text { Gage, } \boldsymbol{g} \\
\text { (mm) }\end{array}$ & 25.4 & 50.8 & 25.4 & 25.4 & 50.8 & 25.4 & 25.4 & 25.4 & 25.4 & 25.4 \\
\hline $\begin{array}{c}\text { Pitch, } \boldsymbol{s} \\
\text { (mm) }\end{array}$ & - & - & 25.4 & 38.1 & 25.4 & - & 25.4 & 38.1 & 50.8 & 63.5 \\
\hline
\end{tabular}

\subsection{Modelling strategy using XFEM approach.}

A physically-based constitutive model implemented were shown in Fig. 2 based on traction-separation relationship. The maximum cohesive stress are given at the maximum separation length and this value is equivalent to un-notched plate strength, $\sigma_{o}$ and area under the curve is equivalent to fracture energy values, $G_{c}$ both parameters are regarded as material properties. XFEM region were assigned within net-section failure path to allow crack propagation in order to allow quicker convergence.

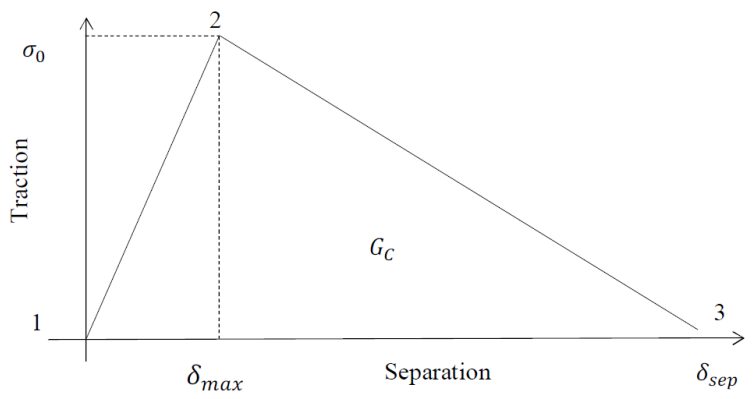

Fig. 2. Physically-based constitutive model used in current work.

The mesh ahead of hole edge were refined and remaining plate regions were made coarser to save computational effort as shown in Fig. 3. Full integration method were implemented to avoid hour-glassing effect (in case of using reduced integration technique). Boundary condition at left edge is made fixed and applied displacement was assigned at the right edge. A sensitivity study on damage stabilization coefficient and meshing refinement for 2-D multi-hole arrangement were carried out, sufficient damage stabilization coefficient and meshing were determined and used in other configurations series models to ensure strength prediction values used were free from these parametric variables. In current study, damage stabilization value of $1 \times 10^{-5}$ was implemented throughout all models and firstorder plane stress element with element designation code of CPS4 was used as element type. These element were chosen as only first-order elements were compatible in current standard ABAQUS Version 6.13 with XFEM framework. 


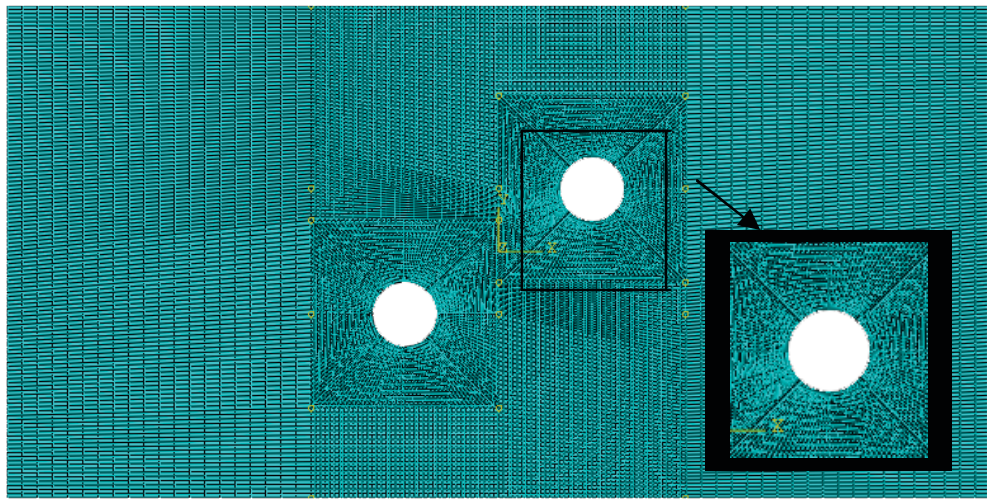

Fig. 3. Meshing of multi-hole FEA model (the vicinity of the hole edge are enlarged for clear visibility)

\section{Results and Discussions}

The stress distribution analysis and strength prediction works were given in the following sub-sections.

\subsection{Stress distribution along hole boundary}

As a result of discontinuities in composite plates, the stress raisers were seen at the notch edge, as expected. Fig. 4 gives the stress contour of multi-bolt plate configurations (a) staggered two holes and (b) single-row three holes. As seen from Fig. 4 (a), the expected crack path was passing through all staggered holes, suggesting stress transfer from the adjacent holes and producing "zig-zag" pattern. On the other hand, Fig. 4(b) showing appreciable stress profile across single row hole along net-section plane and giving crack path in along net-section plane perpendicularly to applied load through three neighbouring holes. These behaviour is consistent with experimental observation reported by Cunningham [2].
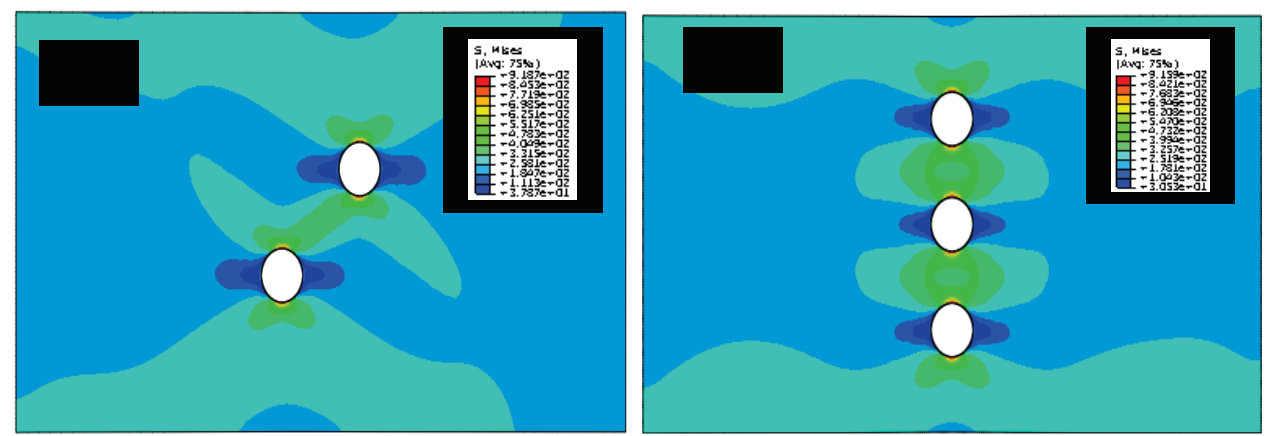

Fig.4. Stress distribution contours of (a) two staggered holes (testing plate D) and (b) three single-row hole (testing plate G) with applied remote stress of $250 \mathrm{~N} / \mathrm{mm}^{2}$.

In three holes configurations, it was found that pitch distance played a vital role to alter the stress distribution profile, smaller pitch distance (Fig. 5(a)) showed appreciable contours passing through all three holes diagonally to applied loading, and shifting to along net-section plane across two vertical holes (Fig. 5(b)) occurred transversely to applied 
loading. This stress contours suggesting crack path to develop following these stress contours, as seen in experimental observations [2].
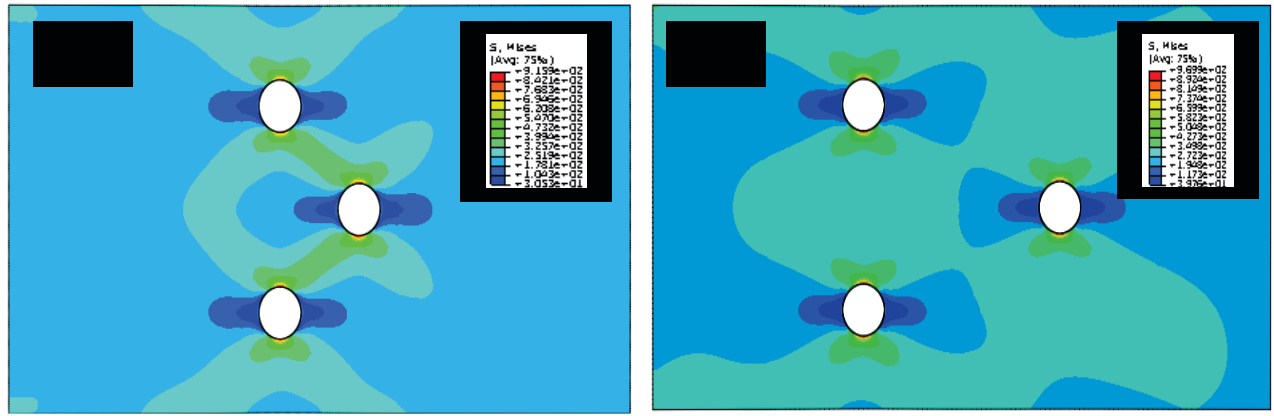

Fig. 5. Stress distribution contours of three staggered holes with (a) pitch distance $=25.4 \mathrm{~mm}$ (testing plate $\mathrm{H}$ ) and (b) pitch distance $=63.5 \mathrm{~mm}$ (testing plate L) with applied remote stress of $300 \mathrm{~N} / \mathrm{mm}^{2}$.

\subsection{Strength prediction using XFEM}

The notched strength from XFEM predictions of all multi-hole configurations understudied were validated against experimental results. The notched strength is given as, $\sigma_{\mathrm{N}}=P_{\max } /$ $A_{n, n s}$ where $A_{n, n s}$ is net-section area, following specification by Cunningham [2]. Fig. 6 showed visible crack path as observed in XFEM modelling work, consistent with experimental observation as found by Cunningham [2].
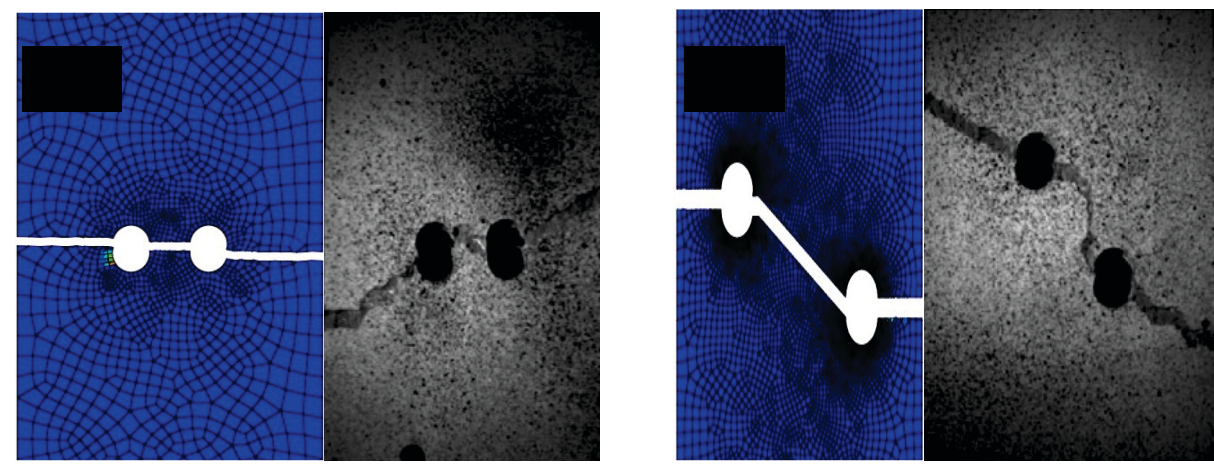

Fig. 6. Visible crack path showed in XFEM model and compared with experimental observations [2] (a) testing series $B(b)$ testing series $\mathrm{E}$.

Table 3 compared the experimental datasets taken from Cunningham [2] work and current XFEM prediction results. The discrepancy found were ranging between $8 \%-31 \%$ (mostly gives less than 25\% discrepancy). The smallest discrepancy were given in single hole plates configuration, is relatively simple as there is no neighbouring stress effect from adjacent hole as seen in other multi-hole configurations. Good prediction in these hole type is much expected. As the plate getting thicker, better notched strength predictions were found, this is due to better representative of "smeared-out" properties in thicker lay-up. Bear in mind the "smeared-out" properties were determined independently by the respective researchers [2]. 
Table 3. Comparison between XFEM prediction and experimental datasets

\begin{tabular}{|c|c|c|c|c|}
\hline Testing Series & $\begin{array}{l}\text { Thickness, } t \\
\quad(\mathrm{~mm})\end{array}$ & $\begin{array}{l}\text { Experimental } \\
\text { notched } \\
\text { strength, } \sigma_{\text {exp }} \\
(\mathrm{MPa})\end{array}$ & $\begin{array}{c}\text { XFEM } \\
\text { notched } \\
\text { strength, } \\
\sigma_{\text {exp }} \text { (MPa) }\end{array}$ & $\begin{array}{c}\text { Discrepancy } \\
(\%)\end{array}$ \\
\hline \multirow{2}{*}{ A } & 6.4 & 336 & 362 & 8 \\
\hline & 12.7 & 276 & 317 & 15 \\
\hline \multirow{2}{*}{ B } & 6.4 & 299 & 229 & -23 \\
\hline & 12.7 & 277 & 232 & -16 \\
\hline \multirow{2}{*}{$\mathrm{C}$} & 6.4 & 339 & 239 & -29 \\
\hline & 12.7 & 299 & 229 & -23 \\
\hline \multirow{2}{*}{$\mathrm{D}$} & 6.4 & 314 & 231 & -26 \\
\hline & 12.7 & 285 & 197 & -31 \\
\hline \multirow{2}{*}{$\mathrm{E}$} & 6.4 & 314 & 263 & -16 \\
\hline & 12.7 & 295 & 260 & -12 \\
\hline \multirow{2}{*}{$\mathrm{F}$} & 6.4 & 330 & 256 & -22 \\
\hline & 12.7 & 297 & 247 & -17 \\
\hline \multirow{2}{*}{ G } & 6.4 & 330 & 235 & -29 \\
\hline & 12.7 & 301 & 228 & -24 \\
\hline \multirow{2}{*}{$\mathrm{H}$} & 6.4 & 314 & 263 & -16 \\
\hline & 12.7 & 305 & 267 & -12 \\
\hline \multirow{2}{*}{$\mathrm{J}$} & 6.4 & 358 & 265 & -26 \\
\hline & 12.7 & 342 & 249 & -27 \\
\hline \multirow{2}{*}{$\mathrm{K}$} & 6.4 & 384 & 291 & -24 \\
\hline & 12.7 & 348 & 314 & -10 \\
\hline \multirow{2}{*}{$\mathrm{L}$} & 6.4 & 405 & 291 & -28 \\
\hline & 12.7 & 344 & 261 & -24 \\
\hline
\end{tabular}

Less good predictions in staggered hole arrangement than non-staggered hole (singlerow holes) is due to existence of diagonal crack path that was not explicitly captured in XFEM techniques. Maximum principal stress (Maxps) failure criterion only revealed crack formation perpendicularly to the maximum principal stress developed. However, not all staggered multi-holes configurations were showing diagonal crack across staggered crack path, larger pitch to gage distance $(\mathrm{p} / 2 \mathrm{~s})$ may demonstrates net-section failures perpendicularly to applied load. Cunningham [2] found that with similar hole numbers, staggered hole gives lower notched strength than non-staggered hole configuration which may requires further investigation, as staggered hole were expected to exhibit larger notched strength than non-staggered holes counterparts. Predictions from XFEM showed that strength prediction in staggered holes were larger than non-staggered arrangement, as it was expected theoretically. Reverse finding by Cunningham [2] leading to larger discrepancy in XFEM predictions as compared to experimental results.

Larger discrepancy in all configurations investigated are primarily due to apparent fracture energy, $\mathrm{G}_{\mathrm{c}}{ }^{*}$ implemented was based on woven fabric GFRP system. It is expected 
that trans-laminar energy value in unidirectional composites are larger than woven fabric composite system counterparts. Fracture energy in woven fabric system is more uniform throughout plate thickness than uni-directional composite due to ability of crimp to arrest crack formation. Therefore under-prediction of all notched strength prediction in all multihole configurations is perhaps not surprising.

\section{Conclusions}

A study on notched strength prediction of various multi-hole configurations with different pitch and gage distances were investigated. A physically-based constitutive model was incorporated, used within XFEM framework to track crack propagation visibly and consistence with experimental observations were found. Current work used independently measured unnotched strength but implemented apparent fracture energy value which is based on woven fabric GFRP system found from other literatures. The strength prediction can be further improved by independently measured fracture energy value. Combination of thicker and non-staggered hole configuration gives relatively good prediction than other multi-hole configurations.

The authors would like to acknowledge Universiti Tun Hussein Onn Malaysia for providing laboratory facilities and financial assistance under project Vot No. U549.

\section{References}

[1] H.M.S. Belmonte, S.L. Ogin, P.A. Smith and R. Lewin, A Physically-based Model for the Notched Strength of Woven Quasi-isotropic CFRP Laminates, Comp. Part A, 35, 763-778, (2004)

[2] D. Cunningham, K.A. Harries and A.J. Bell, Open-hole tension capacity of pultruded GFRP having staggered hole arrangement, Eng. Struct., 95, 8-15, (2015)

[3] British Standards Institution, Design of Steel Structures, EC3, BSI, London, (2005)

[4] S. Chutima and A.P. Blackie, Effect of Pitch Distance, Row Spacing, End Distance and Bolt Diameter on Multi-fastened Composite Joints, Comp. Part A : Applied Science and Manufacturing, 27(2), 105-110, (1996)

[5] N. Moës, N. Sukumar, B. Moran and T. Belytschko, An Extended Finite Element Method (X-FEM) For Two and Three-Dimensional Crack Modeling, ECCOMAS, (2000)

[6] H. Ahmad, A.D. Crocombe and P.A. Smith, Physically Based Finite Element Strength Prediction in Notched Woven Laminates under Quasi-static Loading, Plas. Rubb. \& Comp. 42(3), (2013)

[7] H. Ahmad, A.D. Crocombe and P.A. Smith, Strength Prediction in CFRP Woven Laminate Bolted Double-Lap Joints under Quasi-static Loading using XFEM, Comp. Part A, 56, 192-202, (2014)

[8] H. Ahmad, A.D. Crocombe and P.A. Smith, Strength Prediction of Notched Woven Composite Plates Using a Cohesive Zone Approach, Advan. Material Researcher, 845, 199-203, (2013)

[9] C.T. McCarthy, M.A. McCarthy and V.P. Lawlor, Progressive Damage Analysis of Multibolt Composite Joints with Variable Bolt-hole Clearances, Comp. Part B , 36(4), 290-305, (2005) 